\title{
Principles and Practices of Caring Communities in Educational Practices within Diverse Contexts
}

\author{
Susan Francis Carson
}

\begin{abstract}
Educational opportunities have the potential to increase equity on local as well as global scales. Identifying principles and practices associated with caring communities and equity opportunities (particularly for vulnerable populations) to participate in these communities is not targeted in reform efforts - even though it may significantly enhance student achievement, critical thinking, democratic citizenship, relationships and general satisfaction in a learning community. The identification of principles and practices of caring communities holds schools responsible not just for outcomes, but for the opportunities and choices they offer (Noddings, 2005) [1]. This paper will examine the importance of principles and practices of caring communities in two distinct educational settings, and explore how to infuse them into these settings, creating an exponential effect.
\end{abstract}

Index Terms - Care, educational communities, equity, vulnerable populations.

\section{INTRODUCTION}

As an educator devoted to furthering equitable practices within my field, the concept of principles and practices of caring communities is vital to the trajectory and sustainability of educational transformation for all, including women, low-income individuals, and others traditionally left behind in our education systems. The overall objective of this study was to research the multifaceted and interconnected factors that influence the sustainability of caring educational communities within diverse contexts. The research was designed to be inclusive, with a particular emphasis on the principles and practices that women identify within educational settings.

There also was ongoing collaborative work regarding principles and practices of caring communities in the United States between Grand Valley State University (GVSU) and Coit Creative Arts Academy (CCAA) in Grand Rapids, Michigan. This work was structured to offer a program of university-level courses in the setting of an urban, public, elementary school that serves homeless youth. I wanted to understand how principles and practices of caring communities would apply within the multiple demographics of schools like CCAA.

The consideration of educational opportunities in conjunction with social and structural realities is inherently multifaceted. One facet is to understand how principles and practices of caring communities might be integrated into educational institutions and programs to advance the equity of all. This study at both locations was designed to create a

Manuscript received December 14, 2019; revised March 10, 2020.

Susan Francis Carson is with Grand Valley State University, USA (email: carsons@gvsu.edu). greater understanding of the relationship that principles and practices of caring have to learning and teaching. In addition, this research explored how we can empower others to care, including all demographics.

\section{METHODS}

In exploring ways in which principles and practices of caring communities could be

integrated into a learning community-i.e., how those principles could be used to construct a shared vision, reduce violence, improve communication, enhance relationships, address issues of gender equity, and foster respect-we used a contrast/comparative perspective grounded in anthropological inquiry and action and narrative research methods. Data were collected from numerous sources in both geographic settings to enhance reliability, including surveys, interviews, videos, and field notes. All forms of data were analyzed for indicators of principles and practices such as: (a) development of a climate to address issues of gender, equity, and opportunity; (b) enhanced communication; (c) increased respect and integrity; (d) healing opportunities; and (e) overall increase in job satisfaction, including satisfaction with work.

Within the macro context of both situations, we analyzed the data according to steps in a methodology described by Glaser and Strauss (1967) [2]. Initial categories and concepts were identified. Then, as new data were collected and analyzed, the categories and concepts were continually refined. Data collection and analysis became a honing process, with new information enriching and guiding the focus of the overall research. As categories emerged and grew, we tested larger themes or frameworks to develop hypotheses, which were continually tested against new data.

In addition to this data analysis process, we conducted regular debriefing sessions with the participants in each setting throughout the project. While gathering additional information, these sessions also served as opportunities to check in during analysis.

\section{CONTEXT OF THE RESEARCH}

To create educational environments based upon such principles and practices, leaders need to promote collaboration and shift teaching attitudes toward pedagogy to improve learning and ultimately create a culture of caring (Liontos, 1992) [3]. As educators, it is imperative to understand ourselves and examine our alliances in relation to self and others. For example, Johnston and Pagano (2006) [4] discussed the importance of teaching students how to be responsible to others. When we pass this understanding on 
to our students, we are preparing them to care (Noddings, 2005) [1]. This requires a shift in how we achieve our goals. Of course, principles and practices of caring take on the unique nature of the institution they were conceived from, which means our understanding and implementation of caring will vary greatly. However, caring will be at the core.

To enhance the preparation of teachers to be effective in creating more caring learning environments and stronger community alliances, a new framework for best practices is required. In the vastly diverse milieu within education today, the notion that one preparation fits all future teaching positions ignores society's diversity. Beardall, Bergman, and Surrey (2007) [5] have created a framework for interpersonal connection related to learning. They contend that acknowledging the centrality of connection is imperative in teaching and learning-that it creates opportunities to build healthy relationships in culture and gender and influence one another positively.

\section{THEORETICAL FRAMEWORK}

The challenge of creating and maintaining care in our work often appears unattainable - an insurmountable problem of assimilation. Each educational community, as well as each educator, must identify their own developmental relationships and institutional communities must identify what they value regarding care and well-being. There is not a one-size-fits-all model but rather it is an allinclusive process. Care and well-being become a reflection of the educator and institution from which they were created.

The theory set that became the over-arching theoretical framework for this study was that of analytical/developmental and social theories in the form of Supportive Learning Communities and the four core elements therein:

1) school/community/family involvement;

2) standards/ measures to support continuous improvement;

3) systematic approaches to support safety and positive behavior; and

4) building a supportive learning community (Learning First Alliance, 2001).

\section{A. School/Community/Family Involvement}

Belonging to a caring community of learners, honors and respects the individual while creating a sustainable work environment. Each institution, surrounding community, families, students, teachers and staff must work together to identify specific factors of their supportive learning community (SLC). Some examples could include, curriculum co-designed by the SLC; respectful caring and supportive relationships; and a safe non-judgmental learning environment free from harm and fear.

\section{B. Standards/Measures to Support Continuous Improvement}

Accountability is important and what educators are being held accountable for must include a positive school climate to work and learn in with set standards, the ability to measure progress, and the resources to do our work well.

\section{Systematic Approaches to Support Safety and Positive Behavior}

School climate that maintains respect, stability and compassionate relationship development creates an environment where students, teachers, staff and families will know they are safe and valued. As such it will be a climate that has room for severe and reoccurring behavior problems. The entire SLC will be involved in designing and supporting school rules, discipline practices, consequences and a continuum of supports. All school personnel must be appropriately taught early identification and intervention strategies. NO STUDENTS WILL BE SUSPENDED OR EXPELLED ALL WILL BE INCLUDED, NO ONE WILL BE TURNED INTO THE STREETS.

\section{Building a Supportive Learning Community}

Schools do not exist in a vacuum. Engage the community. Open the arms and heart of the school. Co-design curriculum and professional development that aligns with community, family, student and teacher needs. Remember to ask for help. Value, demonstrate, and celebrate the importance of all members of the SLC. Listen, respect, empathize and be compassionate for yourself and others.

\section{DEMOGRAPHICS: GVSU COLLEGE OF EDUCATION AND CCAA}

GVSU currently has a total enrollment of approximately 25,000 students. As of Fall 2017 the College of Education enrolled 1,594 students; of these 1,172 were female and 422 were male. The vast majority identified themselves as White (89\%), while 5\% identified as Hispanic or Latino, 2\% as African American or Black, and $4 \%$ as other ethnic identifications (GVSU Program Summary for College of Education, 2017) [6].

The CCAA elementary school had an enrollment of 286 students as of 2018 , with $84 \%$ coming from low-income families. Forty-six percent were female and $54 \%$ were male, with $34 \%$ identifying as Black, $31 \%$ as White, and $21 \%$ as Hispanic. With a Michigan state average of $46 \%$ for standardized test scores in English proficiency, 31\% of CCAA students met standards (GreatSchools.org, 2018) [7].

\section{GVSU/CCAA PARTNERSHIP}

The collaboration offered university-level courses in an urban, public, elementary school that serves homeless youth. Pedagogic coursework was completed through lectures, discussion, and online learning, much of it on site at CCAA. The GVSU students also were paired with teachers and students to work in the classrooms at CCAA, where they gained hands-on experience working in urban education. The CCAA's students received mentoring in academic areas as well as social skills.

In the research conducted during the 20167-2017 academic year, six specific themes of importance emerged for the CCAA and GVSU students. For the elementary students they included a) enhanced academic confidence, b) the importance of individual attention, and c) GVSU students as role models. The university students' themes 
centered on a) the importance of building relationships, b) engagement in learning, and c) the opportunity to examine future careers.

\section{RESULTS}

Research and experience at these two different locations showed that principles and practices of caring communities must be constructed within the site of their future implementation. One size does not fit all. Each institution and its interested stakeholders (e.g., faculty, staff, administration, students, alumni, and board members) must participate in the development of the principles and practices of caring communities they will eventually abide by. While the emphasis in this research, was on the caring communities in conjunction with structural elements of education, it could be expanded to embrace other aspects of policy development in institutional, business, government, and public settings.

This research in both locations demonstrated (a) a deepened understanding of the balance between academic freedom and collegial and professional responsibilities in teaching and endorsing equity, (b) informed practices for a college of education to teach our children/selves how to implement caring, (c) the need for future work in academic climate and relationship building for the equitable enrichment of vulnerable populations, and (d) methods by which educational institutions can build their own principles and practices of caring communities.

The themes about caring communities that emerged throughout the research at both locations grew from what proved to be prevailing questions:

- Is it important to belong to a caring community within our educational setting?

- What sort of caring community do we aspire to be?

- What challenges exist within our current structure and working climate that may hinder the development of common principles and practices for a caring community?

- What practices are necessary if our community is to thrive and what practices would prevent its thriving?

- What principles and practices of caring would shape and sustain the community we aim to be?

- How can we implement the identified principles and practices of caring communities within our educational environment?

Living principles shared by the GVSU/CCAA collaboration eventually emerged. They included (a) the affirmation of inherent dignity within a safe setting; (b) the maintenance of a climate of justice marked by respect, integrity, and caring for each other; (c) the fostering of mutual understanding; (d) the confirmation of freedom of expression with civility; and (e) the expression of individuality within bounds of courtesy, sensitivity, and respect.

\section{DISCUSSION/GOING FORWARD}

The profound work of identifying principles and practices of caring educational communities, revealed gaps in the implementation of care. Fragmented and uncoordinated approaches to the implementation of caring communities contributed to unsuccessful, unsustainable interventions. One strategy that strongly emerged was to advance interdisciplinary practices. It became evident that, to implement and sustain principles and practices of caring communities, educators need to be empowered with interdisciplinary knowledge from the fields of nursing, social work, criminal justice, and education. The siloed approach to care has created a gap between awareness and action. A cultural shift is needed to achieve a threshold of understanding necessary to sustain and implement change in caring educational environments (Murdock, 2017) [8]. The greater the awareness of nurses, social workers, educators, and those involved with criminal justice - and the more they understand multiple perspective of needs - the greater the opportunity for change to occur.

Newell (2010) [9] described interdisciplinary education as a process of answering a question, solving a problem, or addressing a topic that is too broad or complex to be dealt with adequately by a single discipline or profession. It draws on disciplinary perspectives and insights learned in complex situations found through service learning, practicums, or field work.

Thus, to eventually develop principles and practices that actually lead to caring communities, questions about interdisciplinary education and collaborative practice need to be answered:

- What are effective models of interdisciplinary education?

- What strategies are necessary for promoting interdisciplinary education?

- How can effective collaborative practice and team functioning be designed and implemented?

- What curriculum design for daily teaching and learning needs to be developed?

- How can the elements of interactive learning, student-centered and small-group teaching, community-based and service learning, and feedback and evaluation be woven into the curriculum?

- What leadership and organizational changes are necessary, including leadership and management skills; organizational behavior, structure, and dynamics; and conflict management and negotiation?

These and other questions need to be answered in a context of shared vision/shared goals, communication with a sense of purpose and meaning, an environment that fosters collaboration and cooperation, a commitment to equality and empowerment, and the assurance of trust. As this work continues and as we change, we need to teach our students the importance of identifying and integrating principles and practices of caring communities where they live. They, in 
their own time, will take these lessons out in their lives, whether in, Michigan, or somewhere else in the world.

\section{PRINCIPLES AND PRACTICES OF CARING COMMUNities DURING CORONAVIRUS}

"What counts is not the enormity of the task, but the size of the courage," said Matthieu Ricard [10].

The statistics on the impact of the coronavirus are overwhelming and vary vastly depending upon the source. According to the CDC (Center for Disease Control) as of May 13, 2020 there were 4.37 million world-wide confirmed cases of the coronavirus, 1.42 million in the US, and 48,021 in Michigan. Deaths related to this virus are upward of 297,682 individuals. [11] The United Nations predicts that 420 million people will be plummeted into extreme poverty, earning as little as $\$ 2.00$ a day. [12] According to Arif Husain, the chief economist at the World Food Program through the United Nations, in 2020 there will be an increase of an additional 130 million people suffering from lack of food, adding to the current 135 million people already experiencing acute food shortages. [13].

Truly staggering and revealing.

What can we do? A lot. Make financial donations to local as well as international relief programs. CDC Foundation. American Red Cross, Direct Relief, Alight, CAMFED, Feeding America, International Rescue Committee, Lawyers for Good Government Foundation, National Association for the Exchange of Industrial Resources, World Health Organization COVID-19 Solidarity Response Fund, United Way Worldwide.

Simple things we can all do: give blood; reach out to organizations and volunteer, for example help with meal delivery or volunteer virtually; speak up and advocate for those who need help; clean your home and donate items; donate computers possible with local schools and also the National Digital Inclusion Alliance (particularly if you work for an institution that updates computers regularly); start letter writing campaigns; contact local agencies and start a phone check in program.

If you have become unemployed find the right support and seek out benefits. Be professional and contact your employer regarding a return to work. Write and update your budget. Think of ways to 'begin' again. What would you do if you could do anything? Collaborate. Re-envision. How can you use your strengths and assets to take care of yourself and your family?

The Professional Quality of Life Measure (ProQOL)is primarily used to determine the positive and negative effects of assisting individuals who experience trauma. [14] It is a free tool with permission verbiage on the home page. It is currently available in 26 languages. I have used the survey to gage a greater understanding of myself as a service provider. Please see the survey and abridged self-score in Appendix A.

Above all else care, care for yourself, care for others. Connect reach out. Focus on creating positive sustainable relationships. Smile, especially behind a mask. Pause and remember to breathe and relax. Maintain a daily routine. Exercise. Safely get outside, walk. Read, more. Listen to music, particularly new genres. Remember that you can make a difference, every thought of peace and love can make a difference. Be in the moment. Start and end our days in gratitude. Be kind.

\section{APPENDIX \\ Professional Quality of Life Scale (ProQOL) \\ Compassion Satisfaction and Compassion Fatigue (ProQOL) Version 5 (2009)}

When you [help] people you have direct contact with their lives. As you may have found, your compassion for those you [help] can affect you in positive and negative ways. Below are some questions about your experiences, both positive and negative, as a [helper]. Consider each of the following questions about you and your current work situation. Select the number that honestly reflects how frequently you experienced these things in the last 30 days.

1. I am happy.

2. I am preoccupied with more than one person I [help].

3. I get satisfaction from being able to [help] people.

4. I feel connected to others.

5. I jump or am startled by unexpected sounds.

6. I feel invigorated after working with those I [help].

7. I find it difficult to separate my personal life from my life as a [helper].

8. I am not as productive at work because I am losing sleep over traumatic experiences of a person I [help].

9. I think that I might have been affected by the traumatic stress of those I [help].

10. I feel trapped by my job as a [helper].

11. Because of my [helping], I have felt "on edge" about various things.

12. I like my work as a [helper].

13. I feel depressed because of the traumatic experiences of the people I [help].

14. I feel as though I am experiencing the trauma of someone I have [helped].

15. I have beliefs that sustain me.

16. I am pleased with how I am able to keep up with [helping] techniques and protocols.

17. I am the person I always wanted to be.

18. My work makes me feel satisfied.

19. I feel worn out because of my work as a [helper]

20. I have happy thoughts and feelings about those I [help] and how I could help them.

21. I feel overwhelmed because my case [work] load seems endless.

22. I believe I can make a difference through my work.

23. I avoid certain activities or situations because they remind me of frightening experiences of the people I [help].

24. I am proud of what I can do to [help].

25. As a result of my [helping], I have intrusive, frightening thoughts.

26. I feel "bogged down" by the system.

27. I have thoughts that I am a "success" as a [helper].

28. I can't recall important parts of my work with trauma victims.

29. I am a very caring person.

30. I am happy that I chose to do this work. 
(C) B. Hudnall Stamm, 2009. Professional Quality of Life: Compassion Satisfaction and Fatigue Version 5 (ProQOL).

/www. isu. edu/ bhstamm or www. proqol. org. This test may be freely copied as long as (a) author is credited, (b) no changes are made, and (c) it is not sold.

\section{YOUR SCORES ON THE PROQOL}

For a full self-score description please go to the ProQOL website.

Based on your responses, place your personal scores below. If you have any concerns, you should discuss them with a physical or mental health care professional.

\section{Compassion Satisfaction}

Compassion satisfaction is about the pleasure you derive from being able to do your work well. Higher scores on this scale represent a greater satisfaction related to your ability to be an effective caregiver in your job.

\section{Burnout}

Most people have an intuitive idea of what burnout is. From the research perspective, burnout is one of the elements of Compassion Fatigue (CF). It is associated with feelings of hopelessness and difficulties in dealing with work or in doing your job effectively. These negative feelings usually have a gradual onset. They can reflect the feeling that your efforts make no difference, or they can be associated with a very high workload or a non-supportive work environment.

\section{Secondary Traumatic Stress}

The second component of Compassion Fatigue (CF) is secondary traumatic stress (STS). It is about your work related, secondary exposure to extremely or traumatically stressful events. However, if you are exposed to others' traumatic events as a result of your work, for example, as a therapist or an emergency worker, this is secondary exposure. The symptoms of STS are usually rapid in onset and associated with a particular event. They may include being afraid, having difficulty sleeping, having images of the upsetting event pop into your mind, or avoiding things that remind you of the event.

(C) B. Hudnall Stamm, 2009-2012. Professional Quality of Life: Compassion Satisfaction and Fatigue Version 5 (ProQOL). Www.proqol.org. This test may be freely copied as long as (a) author is credited, (b) no changes are made, and (c) it is not sold. Those interested in using the test should visit www.proqol.org to verify that the copy they are using is the most current version of the test.

\section{CONFLICT OF INTEREST}

The author declares no conflict of interest.

\section{AUTHOR CONTRIBUTIONS}

Susan Francis was the sole author of this paper.

\section{REFERENCES}

[1] N. Noddings, The Challenge to Care in Schools: An Alternative Approach to Education, 2nd ed. Columbia University, New York: Teachers College Press, 2005.

[2] B. Glaser and A. Strauss, Discovery of Grounded Theory: Strategies for Qualitative Research, Chicago, IL: Aldine Publishing Co., 1967.

[3] L. B. Liontos, "Transformational leadership," in Eric Digest, Eugene, OR: ERIC Clearinghouse on Educational Management. (ERIC Document Reproduction Service No. ED347636), 1992.

[4] D. K. Johnston and J. A. Pagano, Education for a Caring Society: Classroom Relationships and Moral Action, NY: Teachers College Press, 2006.

[5] N. Beardall, S. Bergman, and J. Surrey, Making Connections: Building Community \& Gender Dialogue in Secondary Schools, Cambridge, MA: Educators for Social Responsibility, 2007.

[6] GVSU Program Summary for College of Education (all Undergraduate Programs). (2017). [Online]. Available: https://reports.ia.gvsu.edu/pgmsum17/col_U_ED.html

[7] Great Schools.org. (2018). Coit Creative Arts Academy. [Online]. Available: https://www.greatschools.org/michigan/grandrapids/5149-Coit-Creative-Arts-Academy/\#Students

[8] R. Murdock. (2017). Michigan Association of Health Plans. ACEs: Growing Awareness and Creating Community. [Online]. Available: http://mahp.org/ace-grant-blog/aces-growing-awareness-andcreating-community

[9] W. Newell. (2010). Educating for a complex world: Integrative learning and interdisciplinary studies. Association of American Colleges and Universities. [Online]. 96(4). Available: https://www.aacu.org/publications-research/periodicals/educatingcomplex-world-integrative-learning-and-interdisciplinary

[10] M. Ricard, Himalaya: Personal Stories of Grandeur, Challenge, and Hope, National Geographic, 2006.

[11] Coronavirus (COVID-19). (2020). Google News. [Online]. Available: https://news.google.com/covid19/map?hl=enUS\&gl=US\&ceid=US:en

[12] K. Linthicum, N. Bulos, and A. Ionova. (2020). Economic devastation wrought by the pandemic could ultimately kill more people that the virus itself. Los Angeles Times. [Online]. Available: https://www.latimes.com/world-nation/story/2020-05-11/more-thana-billion-people-escaped-poverty-in-the-last-20-years-thecoronavirus-could-erase-those-gains

[13] A. L. Dahir. (2020). 'Instead of coronavirus, the hunger will kill us.' A global food crisis looms. New York Times. [Online]. Available: https://www.nytimes.com/2020/04/22/world/africa/coronavirushunger-crisis.html

[14] B. H. Stamn. (2009). Professional Quality of Life: Compassion Satisfaction and Fatigue Version 5. [Online]. Available: https://proqol.org/uploads/ProQOL_5_English.pdf

Copyright (C) 2020 by the authors. This is an open access article distributed under the Creative Commons Attribution License which permits unrestricted use, distribution, and reproduction in any medium, provided

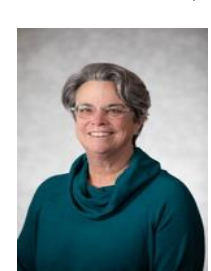
the original work is properly cited (CC BY 4.0)

Susan Francis Carson was born in Mishawaka, Indiana. She attended Antioch University where she received her B.A. (1978) and M.A. (1993) and the Union Institute (1997). Dr. Susan F. Carson is a professor of education in the College of Education at Grand Valley State University in Grand Rapids, Michigan. An ardent advocate of social justice, Dr. Carson's work has involved (a) the establishment of a K-12 school in central Florida for biracial youth; (b) active contributions in peace education - most notably in Chiang Mai, Thailand, at the University of Cape Coast in Ghana, the University of Lucknow, India; Pädagogische Hochschule Schwäbisch Gmünd/University of Education, Schwäbisch Gmünd, Germany; and Ourense, Spain; (c) the reduction of poverty and homelessness in local urban schools; and (d) the empowerment of marginalized populations, including minorities, gay, lesbian, bisexual, and transgendered individuals as well as disabled individuals. She has received the Grand Valley State University Outstanding Community Service Award, Burch, Jacobs and Moore Teaching with Diversity Award, Pew Teaching Excellence Award and is a Fulbright Award recipient. Dr. Carson initiated policy amendments adopted by the US State Department to equitably include partners as family in the Fulbright process. 